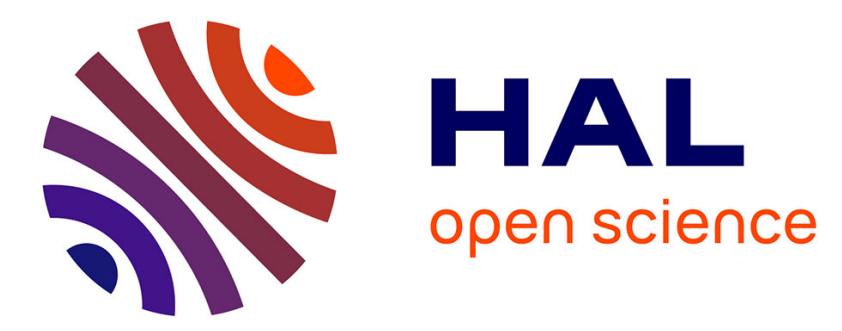

\title{
Remote sensing for assessing vegetated roofs with a new replicable method in Paris, France
}

Tanguy Louis-Lucas, Flavie Mayrand, Philippe Clergeau, Nathalie Machon

\section{To cite this version:}

Tanguy Louis-Lucas, Flavie Mayrand, Philippe Clergeau, Nathalie Machon. Remote sensing for assessing vegetated roofs with a new replicable method in Paris, France. Journal of applied remote sensing, 2021, 15 (01), 10.1117/1.JRS.15.014501] . hal-03263442

\section{HAL Id: hal-03263442 \\ https://hal.sorbonne-universite.fr/hal-03263442}

Submitted on 17 Jun 2021

HAL is a multi-disciplinary open access archive for the deposit and dissemination of scientific research documents, whether they are published or not. The documents may come from teaching and research institutions in France or abroad, or from public or private research centers.
L'archive ouverte pluridisciplinaire HAL, est destinée au dépôt et à la diffusion de documents scientifiques de niveau recherche, publiés ou non, émanant des établissements d'enseignement et de recherche français ou étrangers, des laboratoires publics ou privés. 


\title{
Remote sensing for assessing vegetated roofs with a new replicable method in Paris, France
}

\author{
Tanguy Louis-Lucas $\odot$,* Flavie Mayrand, Philippe Clergeau, \\ and Nathalie Machon $\odot$ \\ Sorbonne Université, Centre d'Écologie et des Sciences de la Conservation \\ (CESCO UMR7204), MNHN, CNRS, Paris, France
}

\begin{abstract}
Vegetated roofs provide many ecosystem services and support urban biodiversity. While it would be interesting to study the contribution of vegetated roofs to ecological corridors, vegetated roofs are listed in no French databases. Because of their intrinsic nature as roofs, their small number, their small size, and the type of vegetation planted on them, vegetated roofs seem to be very difficult to identify. We propose a method to automatically identify vegetated roofs. Using infrared aerial photographs and building shape data, we were able to build a model detecting vegetated roofs using remote sensing and supervised classification techniques. The major difficulty lies in distinguishing between real vegetated roofs and roofs partially covered by tree foliage growing on the ground. In this operation, our classification model obtains an error rate of $\sim 18 \%$. We improve the knowledge of vegetation detection in cities. Moreover, it opens interesting perspectives on the analysis of ecological networks in cities as a function of building height. In addition, it could be an interesting tool for municipalities to monitor urban vegetation development and to prioritize vegetated roofs planning. (c) 2021 Society of Photo-Optical Instrumentation Engineers (SPIE) [DOI: 10.1117/1.JRS.15.014501]
\end{abstract}

Keywords: green roofs; urban vegetation classification; GIS; normalized difference vegetation index.

Paper 200667 received Sep. 10, 2020; accepted for publication Dec. 21, 2020; published online Jan. 11, 2021.

\section{Introduction}

Vegetated roofs are known to provide many ecosystem services in cities. ${ }^{1-3}$ Indeed, they permit better rainwater retention, decrease heat islands, enhance thermal insulation, ${ }^{4-6}$ can improve buildings aesthetics, offer support for biodiversity, ${ }^{3,7}$ sometimes enable food production, ${ }^{8}$ and offer psychological benefits. ${ }^{9}$ Moreover, in an urban densification context, vegetated roofs are opportunities to set up green urban spaces. ${ }^{10}$ These are the reasons why more and more buildings are equipped with such roofs. In 2014, in Paris, for example, the city council decided to create 20 ha of vegetation on roofs and walls. ${ }^{11}$ As of 2016, in France, greening or installing solar panels of roofs became a legal requirement for new commercial surfaces of over $1000 \mathrm{~m}^{2} .^{12}$ To study the ecological role and ecosystem services of roof greening on a large scale, it would be essential to list the number of large-scale vegetated roofs, the area covered, and their localizations. However, in France, these data are not gathered in an accessible geodatabase. Moreover, the scientific literature does not mention a method to easily identify vegetated roofs. The reason for this lack of method is that, to this day, automatic detection of vegetated roofs has been a difficult task. In 2011, Massy et al. ${ }^{13}$ published a semiautomated method for identifying the vegetated roofs in Geneva, Switzerland. This method identified 1747 vegetated roofs, of which only 365 are actually vegetated.

The automated identification of vegetation on roofs in urban environments is difficult because (1) vegetated roofs are very sparse among other diverse types of objects and (2) the very high variability of heights generates errors related to shadows and distortion of aerial photos (photo angle). ${ }^{14}$

*Address all correspondence to Tanguy Louis-Lucas, Tanguy.louis-lucas1@mnhn.fr

$1931-3195 / 2021 / \$ 28.00$ (C) 2021 SPIE 
Therefore, automated identification of vegetation needs very precise geographic data. According to Yan et al., most of the studies on the classification of roofs or vegetation in urban context use LiDAR (Light Detection And Ranging) data, ${ }^{15}$ for example, to estimate the potential for roof greening. ${ }^{16-18}$ The LiDAR can also be used for mapping, for instance to distinguish vegetated areas. ${ }^{19}$ It is sometimes mixed with aerial images, as do Bandyopadhyay et al., ${ }^{20}$ to distinguish trees from buildings. ${ }^{21}$ According to the literature, LiDAR has a better accuracy to differentiate buildings, roofs, and vegetation. Yet, considering LiDAR data price and availability, they can only be used for one-off projects. For example, LiDAR does not cover the city of Paris for free. In cities, aerial photographs should be the base data to easily map vegetated roofs.

The aim of this paper is to present a reproductive method we developed for automatic identification of vegetated roofs, i.e., roofs totally or partially covered with a layer of planted vegetation on a substrate. The uniqueness of the method is based on wisely using basic methods to highlight an object that is hardly detectable, as are vegetated roofs when resorting to the customary use of common tools. It is based on aerial imagery data and buildings polygons. First, we will describe how the method operates, second, how we validated it, and finally, how we applied it to the city of Paris, France, and its inner suburbs.

\section{Description of the Method Development}

\subsection{Reference Site Used for Developing the Method}

The area is located in the Parisian region. The site we have selected to develop our method is a 25- $\mathrm{km}^{2}$ image located in the west of Paris. The image (red square on Fig. 1) straddles several districts of Paris: the 7th, 8th, 15th, and 16th. According to the APUR (Parisian urbanism workshop) data set, ${ }^{22}$ it includes about 25,000 plots of buildings. This reference site was randomly chosen among the squares, which overlap central and periphery zones of the city. We hypothesized that given its situation and size, it contained all types of roofs that can be found in Paris.

This is how our method works: (1) first, the vegetation is identified using indicators. (2) We isolate the roofs covered by vegetation from those potentially vegetated ones. (3) We build a classifier to determine whether these roofs are really vegetated (Fig. 2).

\subsection{Raw Data}

To implement our method, we needed to intersect two generic data. First, accurate and recent infrared aerial photographs to identify vegetation plots location and geometry and second maps
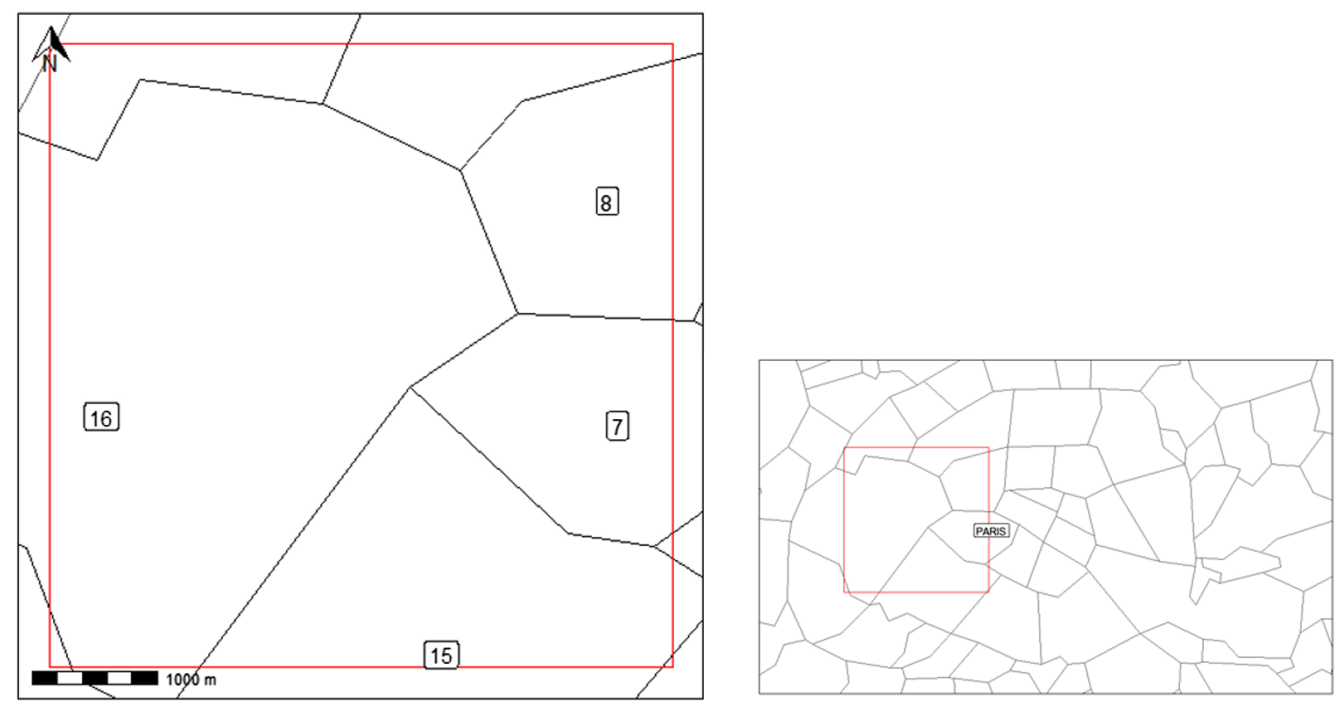

Fig. 1 Site used for developing the method. 


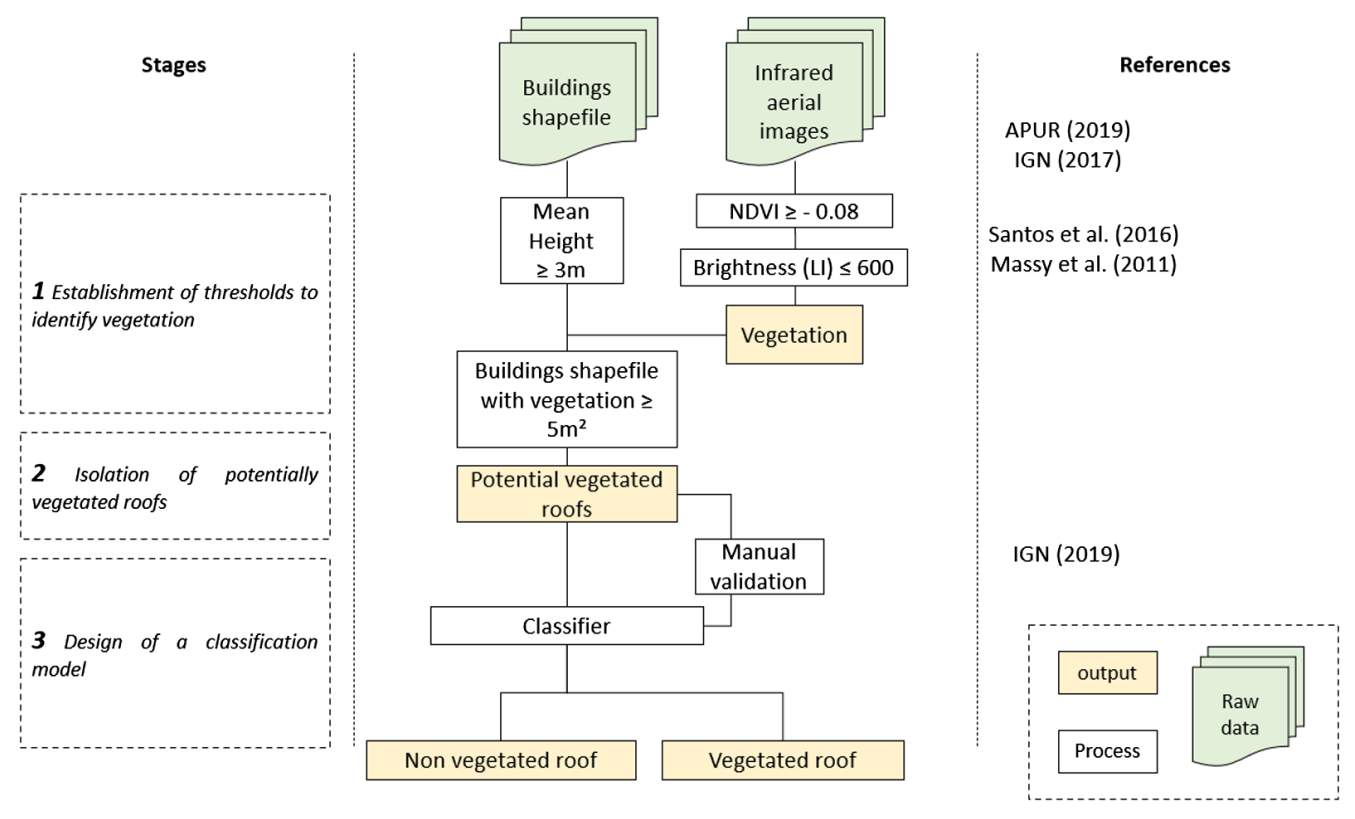

Fig. 2 The functioning of our method; stages and references used.

to identify the buildings' precise locations and geometry. The method is based on two main datasets:

- (1) BD ORTHO IRC, infrared aerial images produced by the IGN (French National Geographic Institute) in 2017, which has three bands: infrared, red, and green and a 50-cm resolution. Among the 13 images available in 2017 for Paris and its suburbs, we used one image of Paris covering $25 \mathrm{~km}^{2}$. This image was chosen because it contains a wide variety of roofs. This image included about 25,000 building shapes.

- (2) The building shapefile produced by the APUR, ${ }^{22}$ which represents the building ground footprint and is based on the cadastral topographic backgrounds. In addition to the buildings' geometry, it contains an average, median, minimum, and maximum height for each building polygon. The shapes are available for free download on the APUR website.

All data processing was performed with Qgis 3.4 and on $\mathrm{R}$ core team 3.6.1. ${ }^{23}$

\subsection{Modeling}

\subsubsection{Identification of potential vegetation on roofs}

Identifying vegetation plots. We calculated the normalized difference vegetation index ${ }^{24}$ (NDVI) by assigning a value ranging from -1 to 1 to each pixel from the French National Institute of Geographic and Forest Information (IGN) infrared image as follows:

$$
\mathrm{NDVI}=\frac{\mathrm{NIR}-R}{\mathrm{NIR}+R}
$$

where NIR is the reflectance in the near-infrared and $R$ is reflectance in the visible red.

The NDVI is based on the differential between the infrared radiation of vegetation leaf cells and the absorption of chlorophyll pigments in the red channel. ${ }^{25}$ This index is proportional to the plant biomass, ${ }^{26}$ and therefore, permits differentiation between tree foliage and herbaceous vegetation. ${ }^{24,26}$

Exclusion of too pale roofs. Some studies estimate the threshold for vegetation NDVI to be 0.2 and values between 0 and 0.2 are described as bare soil. ${ }^{27,28}$ However, vegetated roofs often have short, sparse, and low biomass vegetation, often consisting of stonecrops, with 


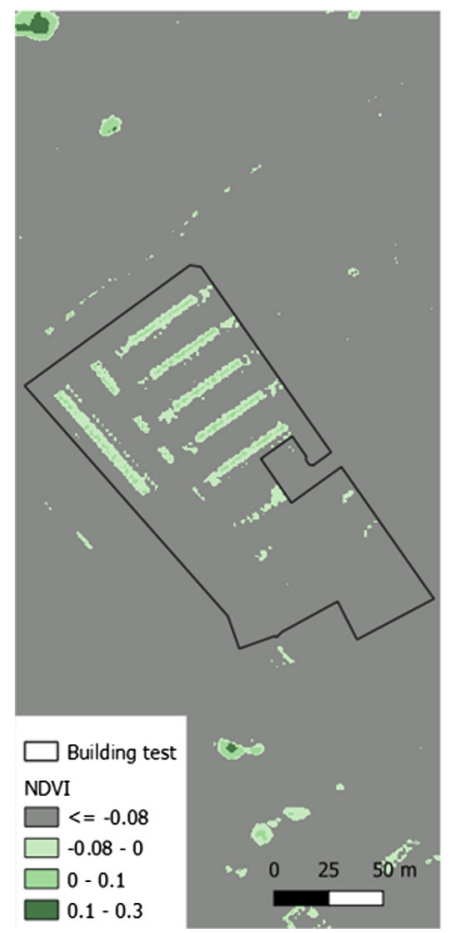

(a)

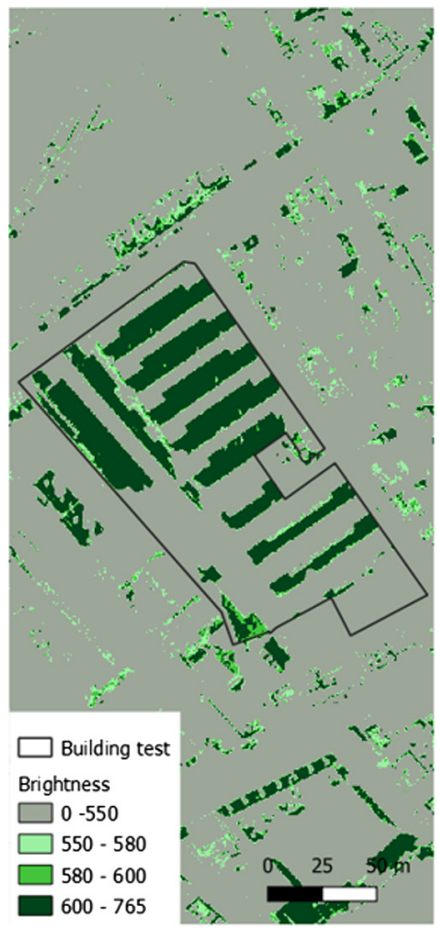

(b)

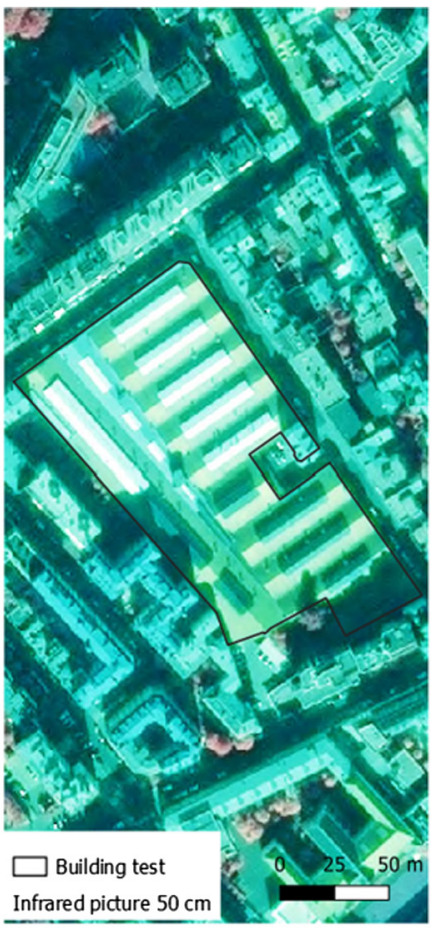

(c)

Fig. 3 Example of a nonvegetated building meeting the NDVI criteria $(\geq-0.08)$. (a) Aerial infrared image, (b) NDVI mapping, and (c) brightness mapping.

an NDVI potentially under 0.2 . Thus, following the Massy et al. ${ }^{13}$ and Santos et al. ${ }^{17}$ approaches, we decided to make a threshold detection of vegetation as NDVI just below 0 (i.e., NDVI $\geq$ $-0.08)$ to limit the number of false negatives. To assess the sensitivity of our analysis, we also tested two other thresholds: NDVI $\geq-0.1$ and $\geq-0.05$.

Exclusion of too bright roofs. The issue is that some urban objects (e.g., Fig. 3) may also have an NDVI level $\geq-0.08$, even though they are not vegetated. A visual check of these cases revealed they displayed metal or partially glazed roofs characterized by very high reflectance. In order not to select these types of roofs, we also calculated for each of them a luminosity index (LI) corresponding to the addition of the three spectral bands from 0 to 765 . We have retained an LI threshold at 600 and tested two others threshold: $\mathrm{LI} \leq 650$ and $\mathrm{LI} \leq 550$.

Intersection of bases. The set of pixels (2) meeting NDVI $\geq-0.08$ and LI $\leq 600$ were isolated and vectorized in the form of a Shapefile layer. We also applied the process with two other thresholds, i.e., (1) for pixels meeting NDVI $\geq-0.1$ and $\mathrm{LI} \leq 650$; and (3) for pixels meeting NDVI $\geq-0.05$ and $\mathrm{LI} \leq 555$. Using Qgis 3.4, the area (in $\mathrm{m}^{2}$ ) of vegetation intersecting each building was assigned to the building polygon as a variable (Area_vege). We decided that $5 \mathrm{~m}^{2}$ was the minimum size and $3 \mathrm{~m}^{2}$ the minimum height for polygons to be considered as vegetated roofs.

Exclusion of roofs partially covered with tree foliage. Some of the roofs are, at least partly, covered with foliage of trees growing at ground level. To discard them, we assumed two hypotheses (Fig. 4): (1) vegetated roofs do not have vegetation around their edges but have a wide area of vegetation over the surface, (2) the foliage of trees has a higher NDVI than other types of roof vegetation. Thus, the 50-cm inner edge of a real vegetated roof must have a max NDVI lower than the part covered by tree foliage.

Thus, we cropped the NDVI maximum value within each roof to a $50-\mathrm{cm}$ internal band. We tested different border sizes $(10,25,50$, and $75 \mathrm{~cm})$ and selected the one enabling us to get the least possible false negatives or false positives. Indeed, to assess our method, we chose a $25-\mathrm{km}^{2}$ 


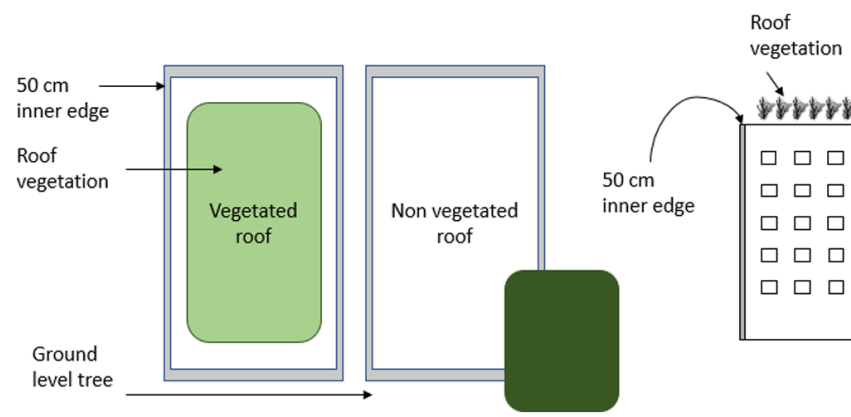

(a)

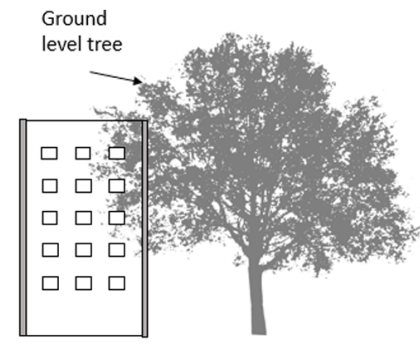

(b)

Fig. 4 Hypothesis to distinguish between real vegetated roofs and roofs partially covered with tree foliage. (a) View from above of vegetated and nonvegetated roofs (the darker the green, the higher the NDVI); and (b) front view.

area on which we compared potential vegetated roofs (detected by the method presented above) with the same roofs using the Geoportal. ${ }^{29}$ This operation allowed us to assign a binary variable called Vrv (vegetated roof validation): 0 if the roof is not vegetated and 1 if the roof is really vegetated. From these different data, we constructed a generalized linear model logistic regression on the software $\mathrm{R}^{23}$ version 3.6.1.

\subsubsection{Designing a classification model}

We defined our logistic regression as did Hosmer et al. ${ }^{30}$

$$
\begin{aligned}
& P\left(\operatorname{Vrv}_{i}=1\right)=\log \left[\frac{P\left(\operatorname{Vrv}_{i}\right)}{1-P\left(\operatorname{Vrv}_{i}\right)}\right] \\
& =a+\beta_{1} \text { NDVImax }_{i}+\beta_{2} \text { Area_vege }_{i}+\beta_{3} \text { NDVImax }_{\text {:area_vege }},
\end{aligned}
$$

where $P\left(\operatorname{Vrv}_{i}=1\right)$ is the probability of an " $i$ " roof being vegetated, "Vrv" is the binary variable $0 / 1$ that visually truly identifies the roof as vegetated or not, obtained through the French Geoportal, $a$ is the intercept of the slope (i.e., the constant term of the slope function), "NDVImax" is the maximum NDVI value of the 50-cm inner edge of each roof, and "Area_vege" represents the area in $\mathrm{m}^{2}$ of vegetation previously identified from NDVI and brightness.

In this model, variables "NDVImax" and "Area_vege" are considered to interact. The model was built with $90 \%$ of roofs $(n=375$, learning data). The remaining $10 \%(n=42)$ were used for model validation.

According to our model summary (see Appendix Table 1), we model the relationships between NDVImax, Area_vege, and our probability to detect vegetative roofs with the following equation:

$$
\begin{aligned}
& P\left(\operatorname{Vrv}_{i}=1\right) \\
& \quad=\frac{\exp \left(-1.02644-16.83121\left(\operatorname{NDVImax}_{i}\right)+0.06277\left(\text { Area_vege }_{i}\right)-0.15456\left(\text { NDVImax }_{i} X \text { Area }_{\text {vege }_{i}}\right)\right.}{1+\exp \left(-1.02644-16.83121\left(\operatorname{NDVImax}_{i}\right)+0.06277\left(\text { Area }_{\text {vege }_{i}}\right)-0.15456\left(\text { NDVImax }_{i} \mathrm{X} \mathrm{Area}_{\text {vege }_{i}}\right)\right.} .
\end{aligned}
$$

This equation is the result of the model obtaining the best accuracy and the best completeness at different thresholds (see Table 2).

Deployment rules are defined classically as ${ }^{31}$

$$
\operatorname{Vrv}_{i}=1 \quad \text { if } P\left(\operatorname{Vrv}_{i}=1\right)>0.5 \quad \text { and } \quad \operatorname{Vrv}_{i}=0 \quad \text { if } P\left(\operatorname{Vrv}_{i}=1\right)<0.5 .
$$

In the rest of this article, we will expose the results derived from the model with the threshold level (2) (i.e. NDVI $\geq-0.08$ and $\mathrm{LI} \leq 600$, See Appendix Table 2). 


\subsection{Validating the Classification Model with the 10\% Remaining Roofs}

In order to validate our model, we used confusion matrices. Confusion matrices are often used in supervised learning to measure the quality of a classifier. These matrices compare actual values to predicted ones. In this way, each predicted value is classified as: true positive (TP), false positive (FP), false negative $(\mathrm{FN})$, true negative $(\mathrm{TN})$. These confusion matrices were used to calculate the error rate, which is the sum of false positives and false negatives relative to the total $n$ of potentially vegetated roofs. The cross-validation $(\mathrm{k}$-fold $=5000)$ gives the average accuracy of our model. Several indicators were calculated from these confusion matrices (see Appendix Table 3).

The results obtained for the three sets of threshold are given in Appendix Table 2. For threshold (2), according to the cross-validation results, the mean error rate was $18 \%$ and the median was $16.7 \%$ (Fig. 5). Our model achieves a $71 \%$ completeness (Completeness is understood here as true positive divided by true positive plus false negative) and an $86 \%$ correctness (Correctness is understood here as true positive divided by true positive plus false positive) $(n=417)$. When we lowered the NVDI and brightness thresholds (threshold (1)), we identified more vegetated roofs (197 vegetated roofs for threshold 1, see Appendix Table 2), but the model accuracy and completeness were weaker. When we increased its threshold (3), we identified much fewer vegetated roofs. The best compromise was obtained for threshold (2). In the continuation of the article, we, therefore, used threshold (2).

The model had a better accuracy for more than $1000-\mathrm{m}^{2}$ roofs. Indeed, good rankings were obtained in $90 \%$ of cases with the learning data and $88 \%$ with validation data. On the contrary, regarding roofs between 200 and $500 \mathrm{~m}^{2}$, the model obtained the lowest accuracy (Fig. 6): $0.84 \%$ and $71 \%$ respectively.

In the following part, we will apply our model to Paris and its inner suburbs in order to map vegetated roofs there.

\section{Results}

\subsection{Application to Paris and Its Suburbs}

The area covers approximately $325 \mathrm{~km}^{2}$ and includes about 75 municipalities, including Paris entirely. The area extends from Cachan $\left(48^{\circ} 47^{\prime} 31^{\prime \prime} \mathrm{N}, 2^{\circ} 19^{\prime} 55^{\prime \prime} \mathrm{E}\right)$ in the south to Gennevilliers $\left(48^{\circ} 56^{\prime} 00^{\prime \prime} \mathrm{N}, 2^{\circ} 18^{\prime} 00^{\prime \prime} \mathrm{E}\right)$ in the north; and from Rueil-Malmaison ( $48^{\circ} 52^{\prime} 40^{\prime \prime} \mathrm{N}, 2^{\circ} 10^{\prime} 53^{\prime \prime}$ E) in the west to Neuilly-sur-Marne $\left(48^{\circ} 51^{\prime} 00^{\prime \prime} \mathrm{N}, 2^{\circ} 32^{\prime} 00^{\prime \prime} \mathrm{E}\right)$ in the east (Fig. 7). It includes
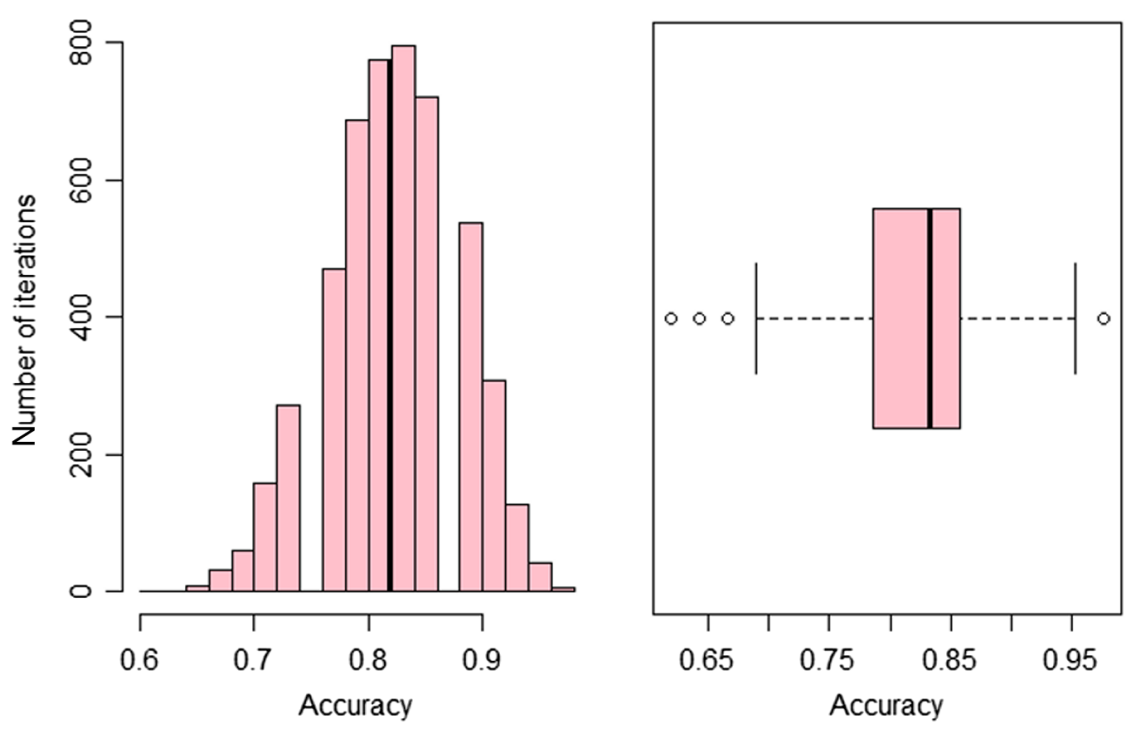

Fig. 5 Model accuracy using 5000 iterations cross validation. Accuracy is understood here as the sum of the right rankings on the population $(n=417)$ of potentially vegetated roofs. 


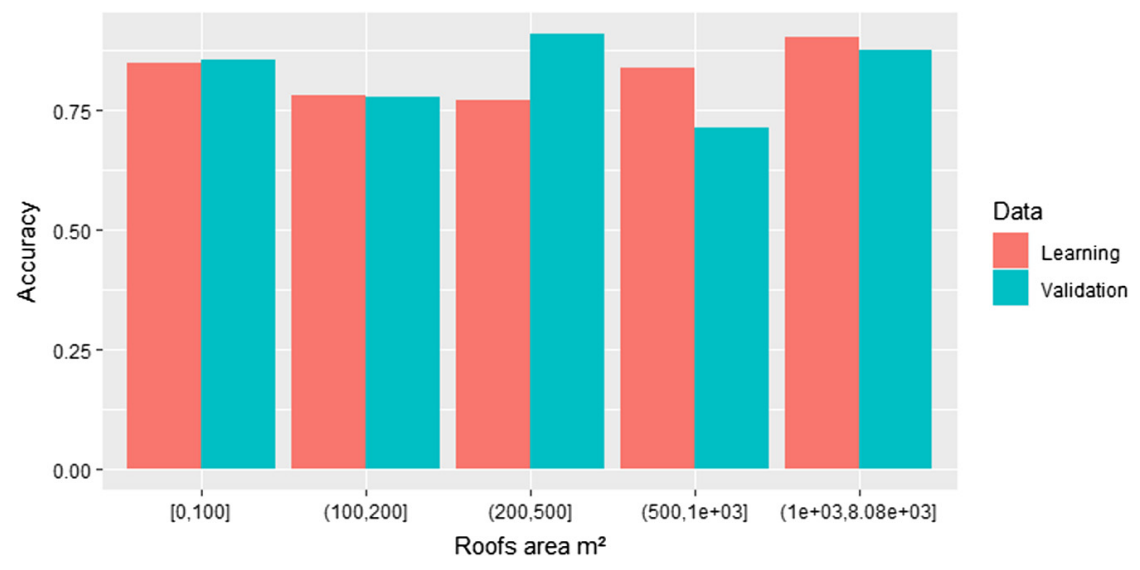

Fig. 6 Model accuracy according to roof area.

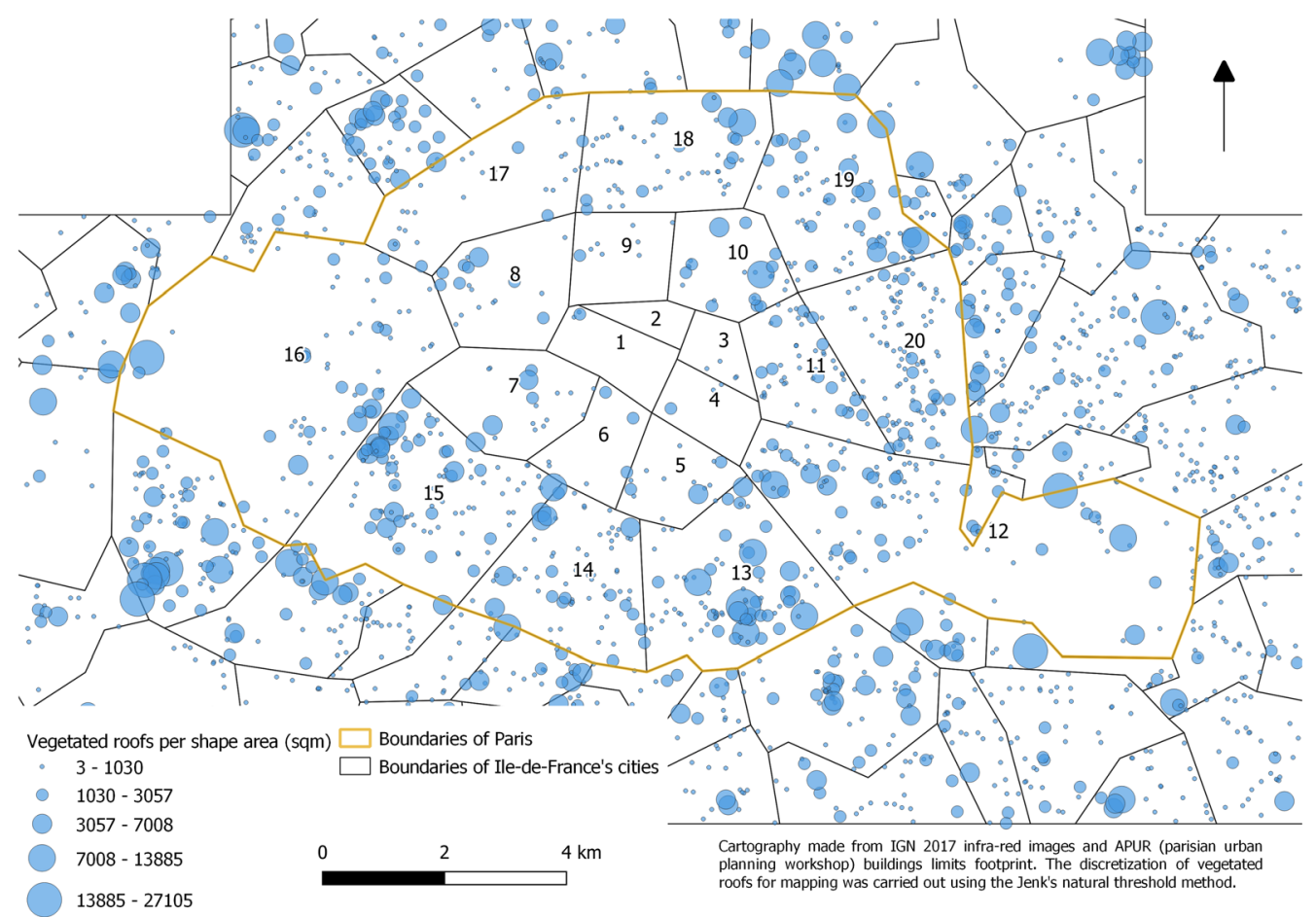

Fig. 7 Vegetated roofs resulting from our modeling, depending on building shape area, centered on Paris.

520,330 buildings or parts of buildings according to the APUR data set. For the year 2017, 13 aerial photographs of the IGN were available.

In the city of Paris, our modeling identified 815 vegetated roofs. In inner suburban cities, 1497 vegetated roofs were recognized. We obtained a cartography of 2312 vegetated roofs in this area (Fig. 7). The number of vegetated roofs represented about $0.5 \%$ of roofs in the study area. The largest vegetated roofs were located on the peripheral Paris arrondissements (districts) or in the inner suburbs. Indeed, Montreuil is the city with the second highest number of green roofs, after Paris (123, Fig. 7). The average vegetated roof surface area is $1069 \mathrm{~m}^{2}$ and the median $421 \mathrm{~m}^{2} .27 \%$ of green roofs have a more than $1,000 \mathrm{~m}^{2}$ surface area [Fig. 8(a)]. The distribution of vegetated roofs is very uneven. Central districts $(1,2,3,4)$ have very few vegetated roofs (between 0 and 4, Fig. 7). The vegetated roofs are concentrated on the edge of Paris and in the cities of the inner suburbs [Fig. 8(b)]. Indeed, one can observe an increase in vegetated roofs' density with distance to the center of Paris (up to $5 \mathrm{~km}$ ); then it decreases until it reaches 0 at around $15 \mathrm{~km}$ from the center of Paris [Fig. 8(b)]. 


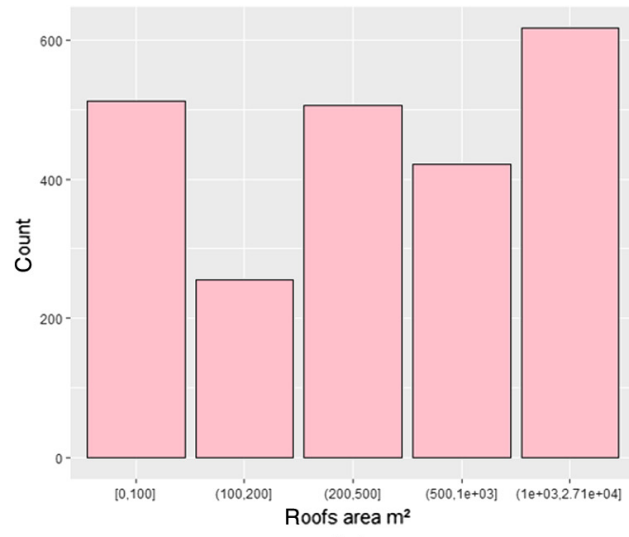

(a)

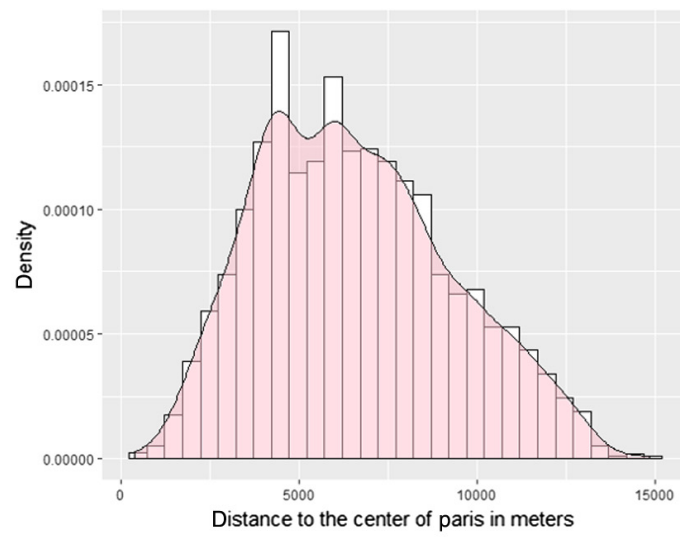

(b)

Fig. 8 Distribution of (a) vegetated roofs sizes and (b) densities in relation to distance from the center of Paris.

\section{Discussion}

The study objective was to provide an easily reproducible automated method for identifying vegetated roofs in cities. These data are essential for the scientific study of urban ecological networks and also for planners trying to improve urban development management.

\subsection{Threshold Setting}

The model we have developed performed well, and therefore, allows automatic identification of vegetated roofs according to several criteria: NDVI, luminosity, and buildings' average height. This model requires only infrared aerial images and a buildings geometry file. The method is probably easily reproducible in other cities in France and abroad. Despite its positive results, our modeling is based on thresholds such as NDVI level and brightness. These choices were based on the technical gray literature, ${ }^{13}$ scientific literature, ${ }^{17,27}$ and the empirical experience of our data. We selected a slightly negative NDVI threshold so as not to overlook very scattered vegetated roofs. To eliminate some errors, the NDVI has been coupled with a brightness index.

We tested different thresholds and selected the one that allowed us to maximize accuracy and completeness (See Table 2). Better data accuracy as well as photographs taken at different dates can account for our improved results.

\subsection{Classification Model Performance}

The construction of a classifier enabled us to relate the greening of a roof to the data obtained by remote sensing. Our model showed a significant relationship between the vegetation level at the edge of the roof and the fact that it is really vegetated. Furthermore, the more pixels we found responding favorably to our filter, the higher the probability that the roof was truly vegetated. Moreover, the relationship between our two explanatory variables allowed us to avoid eliminating roofs both vegetated and covered by trees. In fact, the wider a roof vegetation area, the higher the level of NDVI at the edge accepted by the model.

Contrary to what Yan et al. ${ }^{15}$ mentioned, it is possible with two-dimensional (2D) data to distinguish ground features from elevated features. Indeed, after isolating the potentially vegetated roofs due to our thresholds, our classification model allowed us, with an overall accuracy of about $82 \%$, to differentiate roofs covered by ground level vegetation from vegetated roofs.

Our model tended to show better accuracy on large, over $1000-\mathrm{m}^{2}$ roofs $(88 \%$ to $90 \%)$. It reached an $86 \%$ correctness rate, a better score than Zarea and Mohammadzadeh's, ${ }^{21}$ who obtained a 63\% correctness for tree detection with LiDAR and aerial images. The shortcoming of our model is its completeness score $(71 \%)$. Indeed, $~ 29 \%$ of vegetated roofs were not identified by the classification model, and forgotten vegetated roofs should also be added. More accurate data could improve the completeness score. 
The accuracy level we reached with our method is lower overall than with LiDAR. In fact, Bandyopadhyay et al. ${ }^{20}$ obtained an about $92 \%$ accuracy in urban vegetation and buildings detection rates. However, the data used for our modeling are much more available than the LiDAR data.

\section{Conclusion}

The method we developed here is fully automated and provides good results. Further research would be useful to develop new vegetation indicators in urban contexts.

The setting up of a database of vegetated roofs opens interesting perspectives in the study of the ecological relationships among vegetated roofs. For example, it allows an in-depth analysis of the movement of species from roofs according to the roof characteristics (see roof height). It could fill a knowledge gap as regards the metapopulation dynamics of plant species among roofs. ${ }^{32}$ Tools such as the Graphab software, ${ }^{33}$ originally designed for analyzing ecological networks in rural areas, now induces us to analyze the potential ecological relationships that exist among vegetated roofs. APUR has carried out work to identify roofs with a high potential for vegetalization in Paris; other studies did the same, such as Santos et al., ${ }^{17}$ in Lisbon, and Wong and $\mathrm{Lau}^{18}$ in Hong-Kong. Given these different studies, it would be particularly important to analyze which roofs to prioritize when vegetating to strengthen and improve the Paris urban ecological networks.

\section{Appendix}

The following appendices details the results of the model we used (Table 1), the performance of the model at different thresholds (Table 2), and the detailed performance after selecting a threshold level (Table 3).

Table 1 Model summary table based on threshold 2.

\begin{tabular}{lccccc}
\hline \hline & Estimate & Std. error & $Z$ value & $\operatorname{Pr}(>|z|)$ & \\
\hline (Intercept) & -1.02644 & 0.22481 & -4.566 & $4.97 \mathrm{e}-06$ & $* * *$ \\
NDVImax & -16.83121 & 2.68288 & -6.274 & $3.53 \mathrm{e}-10$ & $* \star \star$ \\
Area_vege & 0.06277 & 0.01262 & 4.973 & $6.58 \mathrm{e}-07$ & $* * *$ \\
NDVImax: AREA_VEGE & -0.15456 & 0.07896 & -1.958 & 0.0503 &. \\
\hline \hline
\end{tabular}

.$=p$-value $\leq 0.1$

${ }^{*}=p$-value $\leq 0.05$

$* *=p$-value $\leq 0.001$

$* * *=p$-value $\leq 0.0001$

Table 2 Model performance according to different thresholds.

\begin{tabular}{lccc}
\hline \hline & Threshold 1 & Threshold 2 & Threshold 3 \\
\hline $\mathrm{NDVI} \geq$ & -0.1 & -0.08 & -0.05 \\
Brightness $\leq$ & 650 & 600 & 550 \\
Potentially vegetated roofs & 536 & 417 & 276 \\
Vegetated roofs using manual validation & 197 & 182 & 121 \\
Prediction accuracy & 0.81 & 0.82 & 0.82 \\
True positive & 113 & 129 & 84 \\
True negative & 321 & 215 & 143 \\
\hline \hline
\end{tabular}


Louis-Lucas et al.: Remote sensing for assessing vegetated roofs with a new replicable method...

Table 3 Summary table of metrics from confusion matrices based on threshold 2 .

\begin{tabular}{lcc}
\hline \hline Parameters & Learning & Validation \\
\hline Accuracy & 0.824 & 0.83 \\
$95 \%$ confidence intervals & $(0.78,0.86)$ & $(0.68,0.93)$ \\
Kappa & 0.63 & 0.64 \\
Sensitivity & 0.91 & 0.96 \\
Specificity & 0.71 & 0.66 \\
Pos Pred value & 0.80 & 0.79 \\
Neg Pred value & 0.86 & 0.92 \\
Prevalence & 0.56 & 0.57 \\
Detection rate & 0.51 & 0.55 \\
\hline \hline
\end{tabular}

\section{Acknowledgments}

We would like to thank Engie Aire Nouvelle for funding this work. We would like to thank for the discussions and proofreading: Elvia Marcellan, Morgane Kerdoncuff, Charles Findling, and Alain Danet. Our warmest thanks to Dominique Macabies (dominique@macabies.fr), our linguistic proofreader, for his work: both very fast and excellent quality. This work was funded by Engie Aire Nouvelle in a partnership with MNHN. The authors declare no conflict of interest. Supplementary material: The following are available online at: https://doi.org/10.24433/CO .2397967.v1

\section{References}

1. L. F. M. Francis and M. B. Jensen, "Benefits of green roofs: a systematic review of the evidence for three ecosystem services," Urban For. Urban Green 28, 167-176 (2017).

2. E. Oberndorfer et al., "Green roofs as urban ecosystems: ecological structures, functions, and services," BioScience 57(10), 823-833 (2007).

3. N. S. G. Williams, J. Lundholm, and J. S. MacIvor, "FORUM: do green roofs help urban biodiversity conservation?" J. Appl. Ecol. 51(6), 1643-1649 (2014).

4. C. Y. Jim, "Green roof evolution through exemplars: germinal prototypes to modern variants," Sustain. Cities Soc. 35, 69-82 (2017).

5. H.-H. Liang and K.-T. Huang, "Study on rooftop outdoor thermal environment and slab insulation performance of grass planted roof," Int. J. Phys. Sci. 6, 65-73 (2011).

6. D. Morau et al., "Thermal behavior of green roof in reunion island: contribution towards a net zero building," Energy Procedia 57, 1908-1921 (2014).

7. F. Madre et al., "Green roofs as habitats for wild plant species in urban landscapes: first insights from a large-scale sampling," Landsc. Urban Plan. 122, 100107 (2014).

8. L. J. Whittinghill, D. B. Rowe, and B. M. Cregg, "Evaluation of vegetable production on extensive green roofs," Agroecol. Sustain. Food Syst. 37(4), 465484 (2013).

9. K. J. H. Williams et al., "Appraising the psychological benefits of green roofs for city residents and workers," Urban For. Urban Green. 44, 126399 (2019).

10. C. Haaland and C. K. van den Bosch, "Challenges and strategies for urban green-space planning in cities undergoing densification: a review," Urban For. Urban Green. 15(4), 760 (2015).

11. Mairie de Paris, "Végétalisons la ville," 2019, https://www.paris.fr/pages/vegetalisons-laville-2459 (accessed 10 March 2020).

12. JORF, "LOI n ${ }^{\circ} 2016-1087$ du 8 août 2016 pour la reconquête de la biodiversité, de la nature et des paysages," https://www.legifrance.gouv.fr/jorf/id/JORFTEXT000033016237/ (2016). 
13. J. Massy, P. Martin, and N. Wyler, "Cartographie semi-automatisée des toitures végétalisées de la Ville de Genève," Géomat. Expert 81, 2631 (2011).

14. P. M. Dare, "Shadow analysis in high-resolution satellite imagery of urban areas," Photogramm. Eng. Remote Sens. 71(2), 169-177 (2005).

15. W. Y. Yan, A. Shaker, and N. El-Ashmawy, "Urban land cover classification using airborne LiDAR data: a review," Remote Sens. Environ. 158, 295-310 (2015).

16. G. Mallinis et al., "Development of a nationwide approach for large scale estimation of green roof retrofitting areas and roof-top solar energy potential using VHR natural colour orthoimagery and DSM data over Thessaloniki, Greece," Remote Sens. Lett. 5(6), 548-557 (2014).

17. T. Santos, J. Tenedório, and J. Gonçalves, "Quantifying the city's green area potential gain using remote sensing data," Sustainability 8(12), 1247 (2016).

18. J. K. W. Wong and L. S.-K. Lau, "From the 'urban heat island' to the 'green island'? A preliminary investigation into the potential of retrofitting green roofs in Mongkok district of Hong Kong," Habitat Int. 39, 25-35 (2013).

19. M. Rutzinger et al., "Object-based point cloud analysis of full-waveform airborne laser scanning data for urban vegetation classification," Sensors 8(8), 4505-4528 (2008).

20. M. Bandyopadhyay et al., "On the fusion of lidar and aerial color imagery to detect urban vegetation and buildings," Photogramm. Eng. Remote Sens. 83(2), 123-136 (2017).

21. A. Zarea and A. Mohammadzadeh, "A novel building and tree detection method from LiDAR data and aerial images," IEEE J. Sel. Top. Appl. Earth Obs. Remote Sens. 9(5), 1864-1875 (2016).

22. APUR, "Atelier Parisien d'Urbanisme," https://opendata.apur.org/ (accessed 10 June 2020).

23. R Core Team, R: A Language and Environment for Statistical Computing.

24. C. J. Tucker, "Red and photographic infrared linear combinations for monitoring vegetation," Remote Sens. Environ. 8(2), 127-150 (1979).

25. A. K. Bhandari, A. Kumar, and G. K. Singh, "Feature extraction using normalized difference vegetation index (NDVI): a case study of Jabalpur City," Procedia Technol. 6, 612-621 (2012).

26. E. Garbolino, "Les plantes indicatrices du climat en France et leur télédétection," thesis, Nice (2001).

27. J. A. Sobrino, J. C. Jiménez-Muñoz, and L. Paolini, "Land surface temperature retrieval from LANDSAT TM 5," Remote Sens. Environ. 90(4), 434-440 (2004).

28. M. M. F. Wong, J. C. H. Fung, and P. P. S. Yeung, "High-resolution calculation of the urban vegetation fraction in the Pearl River Delta from the Sentinel-2 NDVI for urban climate model parameterization," Geosci. Lett. 6(1), 2 (2019).

29. "Géoportail," https://www.geoportail.gouv.fr/ (accessed 18 March 2020).

30. D. W. Hosmer, Jr., S. Lemeshow, and R. X. Sturdivant, Applied Logistic Regression, John Wiley \& Sons (2013).

31. R. Rakotomalala, "Pratique de la Régression Logistique," Régression logistique binaire et polytomique, Université Lumière Lyon, 258 (2015).

32. F. Mayrand and P. Clergeau, "Green roofs and green walls for biodiversity conservation: a contribution to urban connectivity?" Sustainability 10(4), 985 (2018).

33. J.-C. Foltête, C. Clauzel, and G. Vuidel, "A software tool dedicated to the modelling of landscape networks," Environ. Model. Software 38, 316-327 (2012).

Tanguy Louis-Lucas is $\mathrm{PhD}$ student in urban ecology at the National Museum of Natural History in Paris in France. He works on the role of greenroofs in urban green networks. He is supervised by Nathalie Machon and Philippe Clergeau, professors, specialists in urban ecology. They already published many papers on biodiversity in cities.

Flavie Mayrand is a postdoctoral researcher. Her research aims to improve biodiversity of green roofs.

Biographies of the other authors are not available. 